\title{
Temporal sequence learning in reentrantly coupled winner-take-all networks of spiking neurons
}

Jeffrey L McKinstry

From Twenty Second Annual Computational Neuroscience Meeting: CNS*2013

Paris, France. 13-18 July 2013

Patterns of activity in brains are commonly composed of temporal sequences of periods with steady-state firing rates lasting several hundred milliseconds separated by sharp transitions during movement [1], perception [2], and remembering [3]. Although network models involving mean-firing-rate neurons have been used to generate sequential neural activity [1], spiking networks with such capability require further exploration. We describe how large-scale Winner-Take-All (WTA) spiking networks can be coupled together and trained to generate such sequential neural activity. These networks are composed of conductance-based excitatory and inhibitory spiking neurons [4]. Model synapses were subject to short-term synaptic plasticity and spike-timing dependent plasticity (STDP). Each network was a Center-Annular-Surround (CAS) network, a variant of center-surround networks that we have found to effectively generate WTA dynamics in large-scale networks of spiking neurons. Two CAS networks were coupled together reentrantly to form a network capable of sequence learning and recall. We found that networks of this sort can be trained to respond to a sequence of sensory cues by generating temporally ordered patterns of neuronal activity. The patterns consist of brief steady states separated by sharp transitions that resemble those observed experimentally. After training, synaptic changes resulting from STDP acting on connections between the

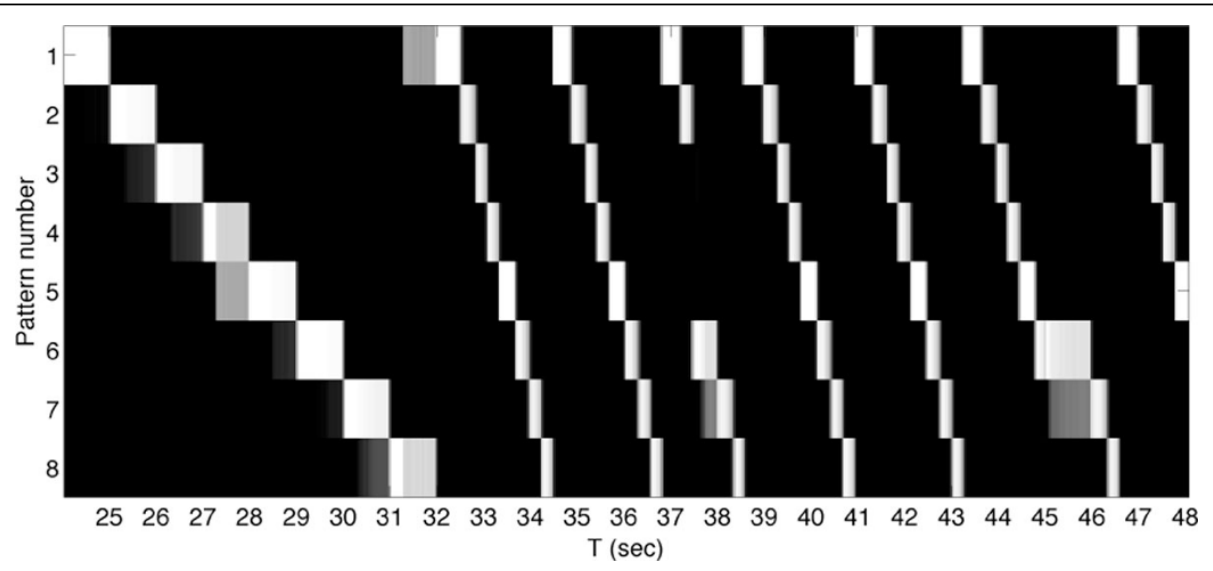

Figure 1 After training, a large-scale network of approximately 4,000 spiking neurons transitions between activity patterns, in the absence of external cues, reflecting the learned sequence

Correspondence: mckinstry@nsi.edu

The Neurosciences Institute, La Jolla, California 92037, USA

(c) 2013 McKinstry; licensee BioMed Central Ltd. This is an Open Access article distributed under the terms of the Creative Commons 
coupled networks formed a link between temporally adjacent patterns of neural activity within the sequence. Figure 1 reflects an analysis of spiking data from this simulated network trained with a repeating sequence of eight cues. Each row in the figure plots the match score over time to one of the eight patterns of neural activity corresponding to one of the cues. White is a perfect match, while black indicates a complete mismatch. The last training repeat is from $t=24$ to $t=32$. Subsequently, external cues were removed and network activity continued, cycling through all eight patterns until another input cue was presented. Then the activity pattern changed to the activity pattern appropriate to the cue presented (see at $t=37$ ), continuing the sequence when the cue was removed. The system was robust with respect to various initial conditions.

We also used the present model to control specific motor sequences in a robotic device. The population activity pattern in this modeled nervous system has similarities to that observed in primate frontal cortex during multisegmented limb movements.

\section{Acknowledgements}

This work was supported in part by DARPA through ONR Grant N00014-081-0728 and AFRL Cooperative Agreement FA8750-11-2-0255 to

Neurosciences Research Foundation. The views, opinions, and/or findings contained in this article/presentation are those of the authors/presenters and should not be interpreted as representing the official views or policies, either expressed or implied, of the Defense Advanced Research Projects Agency or the Department of Defense. Approved for Public Release,

Distribution Unlimited.

Published: 8 July 2013

\section{References}

1. Rhodes BJ, Bullock D, Verwey WB, Averbeck BB, Page MPA: Learning and production of movement sequences: Behavioral, neurophysiological, and modeling perspectives. Human Movement Science 2004, 23:699-746.

2. Jones LM, Fontanini A, Sadacca BF, Miller P, and Katz DB: Natural stimuli evoke dynamic sequences of states in sensory cortical ensembles. Proc Natl Acad Sci USA 2007, 104(47):18772-18777.

3. Seidemann E, Meilijson I, Abeles M, Bergman H, Vaadia E: Simultaneously Recorded Single Units in the Frontal Cortex Go through Sequences of Discrete and Stable States in Monkeys Performing a Delayed Localization Task. J Neurosci 1997, 76(2):752-768.

4. Izhikevich EM, Edelman GM: Large-scale model of mammalian thalamocortical systems. Proc Natl Acad Sci USA 2008, 105(9):3593-3598.

doi:10.1186/1471-2202-14-S1-P271

Cite this article as: McKinstry: Temporal sequence learning in reentrantly coupled winner-take-all networks of spiking neurons. BMC Neuroscience 2013 14(Suppl 1):P271.

\section{Submit your next manuscript to BioMed Central and take full advantage of:}

- Convenient online submission

- Thorough peer review

- No space constraints or color figure charges

- Immediate publication on acceptance

- Inclusion in PubMed, CAS, Scopus and Google Scholar

- Research which is freely available for redistribution

Submit your manuscript at www.biomedcentral.com/submit
C Biomed Central 